Article

\title{
Barriers to Preparing and Cooking Vegetables Are Associated with Decreased Home Availability of Vegetables in Low-Income Households
}

\author{
Matthew J. Landry ${ }^{1, *} \mathbb{( D}$, Marissa Burgermaster ${ }^{1,2}\left(\mathbb{D}\right.$, Alexandra E. van den Berg ${ }^{3}$, \\ Fiona M. Asigbee ${ }^{1}{ }^{\circledR}$, Sarvenaz Vandyousefi ${ }^{1}$, Reem Ghaddar ${ }^{1}$, Matthew R. Jeans ${ }^{1}$, \\ Adelyn Yau ${ }^{1}$ and Jaimie N. Davis ${ }^{1}$ (1) \\ 1 Department of Nutritional Sciences, College of Natural Sciences, University of Texas at Austin, \\ Austin, TX 78712, USA; marissa.burgermaster@austin.utexas.edu (M.B.); fiona.asigbee@utexas.edu (F.M.A.); \\ Sarvenaz.Vandyousefi@nyulangone.org (S.V.); reemghaddar94@gmail.com (R.G.); \\ mjeans@utexas.edu (M.R.J.); adelynyau@utexas.edu (A.Y.); jaimie.davis@austin.utexas.edu (J.N.D.) \\ 2 Department of Population Health, Dell Medical School, University of Texas at Austin, \\ Austin, TX 78712, USA \\ 3 Division of Health Promotion and Behavioral Sciences, Michael and Susan Dell Center for Healthy Living, \\ School of Public Health in Austin, University of Texas Health Science Center at Houston (UT-Health), \\ Austin, TX 78701, USA; Alexandra.E.VanDenBerg@uth.tmc.edu \\ * Correspondence: matthewlandry@utexas.edu
}

Received: 22 April 2020; Accepted: 16 June 2020; Published: 18 June 2020

\begin{abstract}
Knowing which barriers to buying and preparing/cooking vegetables at home are linked with the home availability of vegetables and how food-security status impacts this relationship will facilitate the tailoring of future public health interventions. Baseline data were used from an elementary-school-based intervention. Data on household food-security status, availability of vegetables at home, and barriers to buying and preparing/cooking vegetables were collected from 1942 parents. Differences between food-secure and food-insecure households were examined for barriers to buying and preparing/cooking vegetables. Mixed-effects linear regression was used to estimate the associations between barriers to buying and preparing/cooking vegetables and food-security status on the home availability of vegetables. Food insecurity was reported in $27 \%$ of households. Food-insecure households were significantly more likely to report barriers to buying and preparing/cooking vegetables. The barriers to purchasing/cooking vegetables score was associated with a decrease in the home availability of vegetables score ( $\beta=-0.77 ; 95 \%$ CI: $-0.88,-0.65 ; p<0.001)$. Compared to food-secure households, food-insecure households were $15 \%$ less likely to have home vegetable availability ( $\beta=-1.18 ; 95 \% \mathrm{CI}$ : $-1.45,-0.92 ; p<0.001)$. Although home availability of vegetables does not guarantee consumption, this study identified specific barriers that were associated with availability that can be targeted in future interventions seeking to improve vegetable consumption in the homes of low-income families.
\end{abstract}

Keywords: food security; food insecurity; vegetable availability; barriers; low-income

\section{Introduction}

The 2015-2020 Dietary Guidelines for Americans recommends that Americans consume more vegetables as part of an overall healthy dietary pattern [1]. A diet rich in vegetables can protect against diet-related chronic diseases, including heart disease, type 2 diabetes, obesity, and some cancers [1]. Despite the established health benefits, only 13\% of Americans aged one and older meet the vegetable recommendations [1]. In particular, vegetable consumption in children and young adolescents falls well below recommended intakes [1]. 
Parents and other caregivers exert considerable control over the foods that younger children eat; even as adolescents gain greater autonomy over their dietary choices, the home environment plays a significant role in dietary intake [2-4]. Numerous demographic, psychosocial, behavioral, and socio-environmental factors have been identified as correlates of children's vegetable consumption [5-10]. Higher vegetable consumption during childhood is associated with healthier eating behaviors over a lifetime [11]; therefore, research identifying ways to promote vegetable consumption during childhood is warranted.

There is a direct correlation between food insecurity in households and decreased intake of vegetables among children $[7,12,13]$. The US Department of Agriculture (USDA) describes food security as "access by all people at all times to enough food for an active, healthy life" [14]. A lack of the assured ability to acquire acceptable foods in socially acceptable ways is deemed as food insecurity. Food security involves the intersection of four food-system domains or dimensions: availability, access, utilization, and stability $[15,16]$. Food-insecure households may experience increased barriers to one of these domains, which, in turn, can impact purchasing decisions and dietary consumption.

Availability refers to the ability to obtain quality foods to be consumed [17]. Access is multidimensional and includes physical access to stores or other purchasing locations (farmers' markets or mobile markets), affordability and quality of available produce, and access to vegetables that are seasonally and culturally appropriate [18]. Research has shown that when healthier foods, such as fruit and vegetables, are available and accessible for purchase by a household and are available and accessible in the home, children have higher intakes of vegetables [12,19-21]. The utilization domain of food security has traditionally been overlooked as research has focused on community- or policy-level barriers to availability and access [22]. Utilization incorporates all household practices and individual behaviors in the transformation of food into meals, including planning, management, selection of foods, preparation, and cooking skills $[15,16]$. In some food-insecure households, barriers to utilization, such as limited preparation/cooking knowledge and skills or perceived time constraints, can result in decreased consumption even when vegetables are physically and economically accessible [23].

As children's consumption of vegetables is associated with the home availability of vegetables, a greater understanding of the barriers leading to decreased home availability is needed. Knowledge of how barriers both outside and inside the home environment perpetuate food insecurity would facilitate the tailoring of future public health interventions. This study aimed to examine the association of barriers to buying and preparing/cooking vegetables with the home availability of vegetables and how this relationship differs according to food-security status.

\section{Materials and Methods}

\subsection{Description of Study}

Cross-sectional, baseline parent data from TX Sprouts, a cluster-randomized school-based gardening, cooking, and nutrition intervention, were used. TX Sprouts targeted 3rd to 5th grade students and their parents from 16 elementary schools in the Greater Austin area. Methods for the clinical trial are published elsewhere [24]. Briefly, schools were randomized into one of two groups, namely TX Sprouts intervention ( $n=8$ schools) and delayed intervention ( $n=8$ schools), and data collection occurred in three waves between 2016 and 2019. Schools included in the trial had to meet the following inclusion criteria: (1) a high proportion of Hispanic children $(>50 \%),(2)$ a high proportion of children participating in the free and reduced lunch (FRL) program (>50\%), (3) located within 60 miles of the University of Texas at Austin campus, and (4) no existing garden or gardening program. The trial is registered at ClinicalTrials.gov (NCT02668744).

\subsection{Study Recruitment}

All 3rd to 5th grade students and parents at the recruited schools were contacted to participate via information tables at "Back to School" and "Meet the Teacher" evening events, flyers sent home with students, and teachers making class announcements. 


\subsection{Institutional Review Board}

Written informed consent was obtained from all parents, and assent was obtained from each student. Both consent and assent were required for inclusion in the study. This study was conducted according to the guidelines laid down in the Declaration of Helsinki, and all procedures involving human subjects were approved by the Institutional Review Board of the University of Texas at Austin (IRB\#2014-11-0045) and the individual school district review boards.

\subsection{Data Collection}

At baseline, parents completed a self-administered questionnaire packet that included demographic questions and food-security scales. Questionnaires were completed either at "Back to School" or "Meet the Teacher" evening events or sent home with students, completed by a parent, and returned to school with the student. Questionnaires were provided in both English and Spanish. The questionnaires included questions about child demographics, participation in federal food assistance programs, food and meal choice behaviors, barriers to healthy eating habits, and household food security. Parents received a $\$ 15$ USD gift card to a local grocery store as an incentive for the time spent completing the questionnaire.

\subsection{Assessment of Food-Security Status}

Data on food-security status were collected using the USDA's 18-item Household Food Security Survey Module [25]. Following USDA procedure to calculate a participant's food-security status, the number of affirmative answers were counted. An affirmative answer included answering "yes", "often", "sometimes", "almost every month", or "some months but not every month". The total number of affirmatives was a respondent's raw score. Food-security status was categorized as food-secure (raw score: 0-2) or food-insecure (raw score: 3-18) and analyzed as a dichotomous variable.

\subsection{Availability and Barriers to Buying and Preparing/Cooking Vegetables}

Items assessing home vegetable availability, barriers to buying vegetables, and barriers to preparing/ cooking vegetables were adapted from items used in a similar school-based gardening intervention by Evans and colleagues [26]. The availability of four vegetable types was assessed (fresh; canned, dried, and frozen; salad; and cut-up vegetables within easy reach). Three items assessed barriers to buying vegetables (example: "The stores near me do not sell fresh vegetables") and six items assessed barriers to preparing/cooking vegetables (example: "I don't know how to prepare vegetables"). Full questionnaire items and response options are provided in Table 1.

A continuous variable for the availability of vegetables within the household was created by coding responses (never $=0$, some of the time $=1$, most of the time $=2$, and all of the time $=3$ ) to the four vegetable-type items and summing to $0-12$, with higher scores indicating greater availability. Similarly, continuous variables for the barriers to buying vegetables and barriers to preparing/cooking vegetables were created. Affirmative responses to items were coded as 1 and non-affirmative responses were coded as 0 . After summing responses for each type of barrier, scores ranged from 0-3 (buying barriers) and 0-6 (preparing/cooking barriers), with higher scores indicative of experiencing greater barriers. 
Table 1. Questionnaire items included in the TX Sprouts parent questionnaire assessing availability and barriers to buying and preparing/cooking vegetables. ${ }^{1}$

\begin{tabular}{|c|c|c|}
\hline & Questionnaire Items & Response Options \\
\hline $\begin{array}{c}\text { Availability of } \\
\text { vegetables at home }\end{array}$ & $\begin{array}{l}\text { What foods were available in your home last week? } \\
\text { - } \quad \text { Fresh vegetables } \\
\text { - } \quad \text { Canned, frozen, or dried vegetables } \\
\text { - } \quad \text { Salad } \\
\text { Cut-up fresh vegetables in a place that is easy for kids to reach }\end{array}$ & $\begin{array}{ll}\text { - } & \text { All of the time } \\
\text { - } & \text { Most of the time } \\
\text { - } & \text { Some of the time } \\
\text { Never }\end{array}$ \\
\hline $\begin{array}{l}\text { Barriers to buying } \\
\text { vegetables }\end{array}$ & $\begin{array}{l}\text { Do you experience any of the following challenges when buying } \\
\text { vegetables for meals in your home? } \\
\text { - Vegetables are too expensive } \\
\text { - I cannot find quality vegetables } \\
\text { - The stores near me do not sell fresh vegetables }\end{array}$ & $\begin{array}{ll}\text { - } & \text { Yes } \\
\text { - } & \text { No }\end{array}$ \\
\hline $\begin{array}{c}\text { Barriers to } \\
\text { preparing/cooking } \\
\text { vegetables }\end{array}$ & $\begin{array}{l}\text { Do you experience any of the following challenges when preparing or } \\
\text { cooking vegetables in your home? } \\
\text { - It is hard to use fresh vegetables before they spoil } \\
\text { - My family does not like vegetables } \\
\text { - I do not have time to prepare vegetables } \\
\text { - I do not know how to prepare vegetables } \\
\text { - I do not have simple and quick recipes } \\
\text { My family does not help me cook }\end{array}$ & $\begin{array}{ll}\text { - } & \text { Yes } \\
\text { - } & \text { No }\end{array}$ \\
\hline
\end{tabular}

${ }^{1}$ Questionnaire items were adapted from those used by Evans A., et al. [26].

\subsection{Study Sample}

Of the 4239 eligible children at the 16 schools, 3302 children (or $78 \%$ ) consented to be in the study. Of those who consented, 3135 children ( $95 \%$ of those who consented) completed baseline clinical measures and child surveys and were in the clinical trial. Approximately $92 \%$ (or $n=2876$ ) of parents completed baseline surveys. Of parents who completed baseline surveys, $68 \%(n=1942)$ provided complete data for food security, availability of vegetables, barriers to buying, barriers to preparing/cooking, and their demographics. Missing data were attributable to parents submitting incomplete questionnaires or accidently skipping questions.

\subsection{Statistical Analysis}

Descriptive statistics were used to describe the sample. Chi-squared $\left(\chi^{2}\right)$ tests and univariate linear regression models were used to determine if significant differences existed between the demographic variables of food-secure and food-insecure households. Chi-squared tests were then used to determine whether differences existed between food-secure and food-insecure households in terms of reported barriers to buying and preparing/cooking vegetables. A mixed-effects linear regression was used to examine the associations between the scores for barriers to buying, barriers to preparing/cooking, and food security on the home availability of vegetables score, with random effects at the school level to account for clustering by schools. Interactions between food insecurity and buying and preparing/cooking scores on the home availability of vegetables score were tested. Race/ethnicity, parent education, number of children in the household, and receipt of Supplemental Nutrition Assistance Program (SNAP) benefits were used as covariates. All analyses were conducted using SPSS Statistics for Macintosh, version 24.0 (IBM Corp, Armonk, NY, USA), and an alpha level of $p=0.05$ was used for significance.

\section{Results}

The analytic parent sample $(n=1942)$ was predominantly female $(87 \%)$ and primarily Hispanic $(63 \%)$. Other races/ethnicities that made up the sample were non-Hispanic white (25\%), non-Hispanic black $(9 \%)$, and other races/ethnicities $(3 \%)$. A child's mother or father was the primary questionnaire respondent $(98 \%)$; other respondents were grandparents $(2 \%)$ or other guardians $(<0.5 \%)$. On average, 
households had $2.7 \pm 1.1$ children. Twenty-seven percent of the sample reported household food insecurity. Thirty-two percent of the sample reported receiving SNAP benefits. Comparing demographic characteristics between food-secure and food-insecure households, race/ethnicity was significantly different $(p<0.002)$. Food-secure households were more likely to be non-Hispanic white or of another ethnicity, whereas food-insecure households were more likely to be of Hispanic or non-Hispanic African American race/ethnicity. Education level was also significantly different between food-secure and food-insecure households $(p<0.001)$. Food-secure parents were more likely to have a high school diploma, some college, or a college degree compared to food-insecure parents. There were no other significant differences in demographic characteristics between food-secure and food-insecure households.

The distributions of two of the three barriers associated with buying vegetables were significantly different between food-secure and food-insecure households (Table 2). Food-insecure households were more likely to report that vegetables are too expensive $(p<0.001)$ and being unable to find quality fruit and vegetables $(p<0.001)$. All distributions for barriers associated with preparing/cooking vegetables were significantly different between food-secure and food-insecure households (Table 2), with food-insecure households more likely to report difficulty using fresh vegetables before they spoil $(p<0.001)$, their family not liking vegetables $(p=0.02)$, not having time to prepare vegetables $(p<0.001)$, not knowing how to prepare vegetables $(p<0.001)$, not having simple quick recipes $(p<0.001)$, and their family not helping with cooking $(p<0.001)$.

Table 2. Distribution of reported barriers to buying and preparing/cooking vegetables between food-secure and food-insecure households.

\begin{tabular}{|c|c|c|c|}
\hline Questionnaire Items and Responses & $\begin{array}{l}\text { Food-Secure } \\
\quad(n=1443)\end{array}$ & $\begin{array}{l}\text { Food-Insecure } \\
\quad(n=538)\end{array}$ & $p$-Value ${ }^{\mathrm{a}}$ \\
\hline \multicolumn{4}{|l|}{ Barriers to Buying Vegetables for Meals } \\
\hline Vegetables are too expensive & & & $<0.001$ \\
\hline Yes & 135 & 232 & \\
\hline No & 1308 & 306 & \\
\hline I cannot find quality fruits and vegetables & & & $<0.001$ \\
\hline Yes & 93 & 70 & \\
\hline No & 1350 & 468 & \\
\hline The stores near me do not sell fresh fruits and vegetables & & & 0.108 \\
\hline Yes & 25 & 16 & \\
\hline No & 1418 & 522 & \\
\hline \multicolumn{4}{|l|}{ Barriers to Preparing or Cooking Vegetables } \\
\hline It is hard to use fresh vegetables before they spoil & & & $<0.001$ \\
\hline Yes & 192 & 115 & \\
\hline No & 1251 & 423 & \\
\hline My family does not like vegetables & & & 0.022 \\
\hline Yes & 178 & 88 & \\
\hline No & 1265 & 450 & \\
\hline I do not have time to prepare vegetables & & & $<0.001$ \\
\hline Yes & 36 & 34 & \\
\hline No & 1407 & 504 & \\
\hline I do not know how to prepare vegetables & & & $<0.001$ \\
\hline Yes & 81 & 57 & \\
\hline No & 1362 & 481 & \\
\hline I do not have simple quick recipes & & & $<0.001$ \\
\hline Yes & 187 & 140 & \\
\hline No & 1256 & 398 & \\
\hline My family does not help me cook & & & $<0.001$ \\
\hline Yes & 47 & 47 & \\
\hline No & 1396 & 491 & \\
\hline
\end{tabular}


Results from a mixed-effects linear regression model of the impact of barriers to buying vegetables and barriers to preparing/cooking vegetables on the home availability of vegetables score within food-secure and food-insecure households are provided in Table 3. Each additional barrier to preparing/cooking vegetables was associated with a -0.77 unit decrease in vegetable availability at home (95\% CI: -0.88 , $-0.65 ; p<0.001)$. The barriers to buying vegetables score was not significantly associated with vegetable availability at home. A significant association between food-security status and the availability of home vegetables score was observed $(\beta=-1.18 ; 95 \% \mathrm{CI}:-1.45,-0.92 ; p<0.001)$. Compared to food-secure households, food-insecure households were associated with a $15 \%$ lower availability of home vegetables (mean \pm SE: $8.32 \pm 1.9$ versus $7.14 \pm 1.9$ ). There was a significant association between race/ethnicity and the home availability of vegetables $(p<0.001)$. Compared to non-Hispanic white households, Hispanic households had $7 \%$ lower home availability of vegetables scores ( $\beta=-0.56 ; 95 \% \mathrm{CI}:-1.00,-0.12 ; p=0.01$ ). Compared to non-Hispanic white households, non-Hispanic African American households had $4 \%$ lower home availability of vegetables scores $(\beta=-0.35 ; 95 \% \mathrm{CI}:-0.64,-0.06 ; p=0.02)$ and other race/ethnicity households had $14 \%$ lower availability $(\beta=-1.14 ; 95 \% \mathrm{CI}:-1.76,-0.51 ; p<0.001)$.

Table 3. Mixed-effects linear regression model of the impact of barriers to buying and preparing/cooking vegetables on the home availability of vegetables score in food-secure and food-insecure households.

\begin{tabular}{|c|c|c|c|c|}
\hline Variable & Unstandardized $\beta$ & Standard Error & $95 \%$ CIs for $\beta$ & $p$-Value \\
\hline Race/Ethnicity & & & & 0.001 \\
\hline Non-Hispanic white & Referent & - & - & - \\
\hline Hispanic & -0.56 & 0.23 & $-1.00,-0.12$ & 0.01 \\
\hline Non-Hispanic African American & -0.35 & 0.15 & $-0.64,-0.06$ & 0.02 \\
\hline Other & -1.14 & 0.32 & $-1.76,-0.51$ & $<0.001$ \\
\hline SNAP Benefits & & & & 0.645 \\
\hline No & Referent & - & - & - \\
\hline Yes & 0.06 & 0.13 & $-0.19,0.31$ & 0.645 \\
\hline Food-Security Status & & & & $<0.001$ \\
\hline Food-secure & Referent & - & - & - \\
\hline Food-insecure & -1.18 & 0.14 & $-1.45,-0.92$ & $<0.001$ \\
\hline Parent Education & & & & 0.03 \\
\hline Less than a high school diploma & Referent & - & - & - \\
\hline High school diploma & -0.08 & 0.16 & $-0.39,0.24$ & 0.63 \\
\hline Some college or greater & 0.30 & 0.15 & $0.01,0.60$ & 0.05 \\
\hline Number of Children in the Home & -0.05 & 0.05 & $-0.16,0.05$ & 0.30 \\
\hline BB Score & -0.19 & 0.11 & $-0.41,0.03$ & 0.09 \\
\hline PCB Score & -0.77 & 0.06 & $-0.88,-0.65$ & $<0.001$ \\
\hline
\end{tabular}

Abbreviations: CIs, confidence intervals; SNAP, Supplemental Nutrition Assistant Program; BB, buying barriers; $\mathrm{PCB}$, preparing/cooking barriers.

\section{Discussion}

In this large, cross-sectional examination of home vegetable availability and barriers to buying and preparing vegetables among low-income families in the Greater Austin area of Texas, we found that food-insecure families reported lower vegetable availability and that food-insecure families were more likely to report barriers to buying and preparing/cooking vegetables. However, while barriers to preparing/cooking vegetables were significantly associated with lower vegetable availability, barriers to buying vegetables were not. Although home availability of vegetables does not guarantee consumption, the barriers identified in this study should be considered when designing future interventions for low-income populations.

The home plays a central role in influencing child dietary consumption and may serve as a modifiable target for interventions [27]. There has been evidence that the home availability of vegetables results in a greater intake of vegetables among children [20]. Although the availability of vegetables does not guarantee consumption, children within food-insecure households may have a decreased intake of vegetables compared to their food-secure peers because of reduced availability [28]. However, research 
by Poulsen and colleagues (2019) found that food-security status was not associated with vegetable consumption [12]. Further research is needed to determine the relationship between home vegetable availability and intake among food-insecure children. Our research further explains the nuance of the relationship between household food insecurity and vegetable availability. This study found a significant association between the availability of vegetables and food security, with food-insecure households reporting decreased availability.

Cost has been consistently found to be a major barrier to accessing and purchasing fresh vegetables for low-income individuals [21,29-32]. Qualitative research has reported that low-income households may avoid purchasing vegetables even when available because of the lack of high-quality options [31,33]. Efforts to increase access to fresh produce have resulted in a growing number of vegetable access programs. A recent systematic review reported that the introduction of new food retail opportunities within low-income communities that sell fruit and vegetables may provide a means of accessing fresher and better-quality produce and have more beneficial impacts on overall diet for low-income and food-insecure households compared to traditional grocery stores and supermarkets [34]. Community gardens [35-37] and farmers' markets [38-40], especially those that accept food assistance benefits, have been shown to increase food security and vegetable intake. These programs are most likely to succeed when they simultaneously address multiple barriers to access or when coupled with other interventions or strategies [31].

This study found a null effect for SNAP participation and vegetable availability. There is some research that suggests that receipt of SNAP benefits in addition to associated vegetable incentive programs may increase purchase and consumption of vegetables [41,42]. However, other research has highlighted that recipients still experience incentive eligibility barriers or are unaware that these programs are available to them $[31,43,44]$. Local and federal policies can be utilized to remove or lower incentive eligibility, purchasing hurdles, and access barriers.

While it might be expected that barriers to buying vegetables drive a lower home availability of vegetables in low-income families, barriers to purchasing vegetables were not associated with the home availability of vegetables in our study. While availability was not impacted by access barriers, food-insecure households still reported experiencing access barriers to a greater degree than food-secure households. Emerging research has found that the extent to which differential access to healthy foods is thought to explain nutritional inequalities between low-income and high-income households may be overstated. Differences in nutrition knowledge, preferences, and tastes may have a greater impact than the retail environment [45]. The observed null effect may also be due to the attenuation of the preparing/cooking vegetables barriers score within our model.

This study found that barriers to preparing/cooking vegetables were more likely to be reported in food-insecure households compared to food-secure households. Additionally, this study also found that households that experienced increased barriers to preparing/cooking vegetables were more likely to be associated with a lower home availability of vegetables. These barriers encompass aspects tied to practical food knowledge and skills [46]. A greater amount of time spent on home food preparation is associated with an increased vegetable intake [47]. In the United States, the majority of meals are consumed away from the home [48]; however, there is some research to suggest that cooking at home has increased in recent years [49]. Research has found that food-insecure individuals have a similar frequency of cooking compared to their food-secure peers [50]. However, meals in food-insecure homes are less complex, which may be due to less time spent planning meals or having limited food preparation equipment [27,51].

Lack of meal planning and cooking complexity may also be a result of decreased knowledge and skills in relation to food and nutrition. A study by Begley and colleagues (2019) reported that limited food literacy was associated with greater food insecurity [23]. Knowledge and skills in relation to food and nutrition are a targetable outcome for nutrition education, as they can improve through education and skill development [52]. Prior research has shown that children involved in cooking activities have a higher vegetable intake compared to children who do not help [53-55]. Educating 
parents on successful ways to utilize their child's help, coupled with equipping children with basic cooking skills, may be a potential strategy to overcome this barrier.

This study has several limitations. First, because of the cross-sectional design, only associations, not causal relationships, can be inferred. This study focused on the barriers from store to household that are present for households. These challenges are most likely not unique to our study's population. However, a firm understanding of unique or different population-specific determinants and barriers to intake that may exist is required when developing tailored interventions. While this study controlled for a number of demographic, psychosocial, behavioral, and socio-environmental factors, additional factors may influence this relationship and be critical in guiding future public health efforts.

To adequately address food insecurity and improve vegetable consumption, multilevel strategies that provide additional resources at the individual, household, community, and system levels are needed [22,56]. Future interventions should consider all four of the pillars of food security (availability, access, utilization, and stability) $[15,16]$. This study in particular highlights the need for household-level interventions that focus on overcoming the barriers to preparing and cooking vegetables. These interventions should be delivered in conjunction with food assistance programs or food relief strategies that provide greater financial resources for food within the household [22]. Public health professionals possess the education and competency to make valuable contributions to overcoming barriers and improving the availability of vegetables within food-insecure populations.

Author Contributions: Conceptualization, M.J.L.; methodology, M.B., M.J.L., and A.Y.; formal analysis, M.J.L. and A.Y.; data curation, M.J.L., A.E.v.d.B., F.M.A., S.V., R.G., M.R.J., A.Y., and J.N.D.; writing—original draft preparation, M.J.L. and A.Y., writing—review and editing, M.J.L., M.B., A.E.v.d.B., F.M.A., S.V., R.G., M.R.J., A.Y., and J.N.D.; project administration, A.E.v.d.B. and J.N.D.; funding acquisition, J.N.D. All authors have read and agreed to the published version of the manuscript.

Funding: This research was funded by the National Institutes of Health, National Heart, Lung, and Blood Institute, grant number R01HL123865.

Acknowledgments: The authors would like to thank all of the children and their families for participating in this study. The authors also thank the TX Sprouts staff for being instrumental in data collection.

Conflicts of Interest: The authors declare no conflict of interest.

\section{References}

1. US Department of Health and Human Services; US Department of Agriculture. Dietary Guidelines for Americans 2015-2020, 8th ed.; US Government Printing Office: Washington, DC, USA, 2015.

2. Arcan, C.; Neumark-Sztainer, D.; Hannan, P.; Van Den Berg, P.; Story, M.; Larson, N. Parental eating behaviours, home food environment and adolescent intakes of fruits, vegetables and dairy foods: Longitudinal findings from Project EAT. Public Health Nutr. 2007, 10, 1257-1265. [CrossRef]

3. Loth, K.A.; MacLehose, R.F.; Larson, N.; Berge, J.M.; Neumark-Sztainer, D. Food availability, modeling and restriction: How are these different aspects of the family eating environment related to adolescent dietary intake? Appetite 2016, 96, 80-86. [CrossRef] [PubMed]

4. Rosenkranz, R.R.; Dzewaltowski, D.A. Model of the home food environment pertaining to childhood obesity. Nutr. Rev. 2008, 66, 123-140. [CrossRef] [PubMed]

5. Neumark-Sztainer, D.; Wall, M.; Perry, C.; Story, M. Correlates of fruit and vegetable intake among adolescents: Findings from Project EAT. Prev. Med. 2003, 37, 198-208. [CrossRef]

6. Rasmussen, M.; Krølner, R.; Klepp, K.-I.; Lytle, L.; Brug, J.; Bere, E.; Due, P. Determinants of fruit and vegetable consumption among children and adolescents: A review of the literature. Part I: Quantitative studies. Int. J. Behav. Nutr. Phys. Act. 2006, 3, 22. [CrossRef]

7. Dave, J.M.; Evans, A.E.; Saunders, R.P.; Watkins, K.W.; Pfeiffer, K.A. Associations among food insecurity, acculturation, demographic factors, and fruit and vegetable intake at home in Hispanic children. J. Am. Diet. Assoc. 2009, 109, 697-701. [CrossRef]

8. Lorson, B.A.; Melgar-Quinonez, H.R.; Taylor, C.A. Correlates of fruit and vegetable intakes in US children. J. Am. Diet. Assoc. 2009, 109, 474-478. [CrossRef] 
9. McClain, A.D.; Chappuis, C.; Nguyen-Rodriguez, S.T.; Yaroch, A.L.; Spruijt-Metz, D. Psychosocial correlates of eating behavior in children and adolescents: A review. Int. J. Behav. Nutr. Phys. Act. 2009, 6, 54. [CrossRef] [PubMed]

10. Di Noia, J.; Cullen, K.W. Fruit and vegetable attitudes, norms, and intake in low-income youth. Health Educ. Behav. 2015, 42, 775-782. [CrossRef]

11. Maynard, M.; Gunnell, D.; Ness, A.R.; Abraham, L.; Bates, C.J.; Blane, D. What influences diet in early old age? Prospective and cross-sectional analyses of the Boyd Orr cohort. Eur. J. Public Health 2005, 16, 315-323. [CrossRef]

12. Poulsen, M.N.; Bailey-Davis, L.; Pollak, J.; Hirsch, A.G.; Schwartz, B.S. Household Food Insecurity and Home Food Availability in Relation to Youth Diet, Body Mass Index, and Adiposity. J. Acad. Nutr. Diet 2019, 119, 1666-1675. [CrossRef]

13. Fram, M.S.; Ritchie, L.D.; Rosen, N.; Frongillo, E.A. Child experience of food insecurity is associated with child diet and physical activity. J. Nutr. 2015, 145, 499-504. [CrossRef] [PubMed]

14. Anderson, S.A. Core indicators of nutritional state for difficult-to-sample populations. J. Nutr. 1990, 120, 1559-1600. [CrossRef] [PubMed]

15. Jones, A.D.; Ngure, F.M.; Pelto, G.; Young, S.L. What are we assessing when we measure food security? A compendium and review of current metrics. Adv. Nutr. 2013, 4, 481-505. [CrossRef] [PubMed]

16. Coates, J. Build it back better: Deconstructing food security for improved measurement and action. Glob. Food Sec. 2013, 2, 188-194. [CrossRef]

17. Bryant, M.; Stevens, J. Measurement of food availability in the home. Nutr. Rev. 2006, 64, 67-76. [CrossRef] [PubMed]

18. Rose, D.; Bodor, J.N.; Hutchinson, P.L.; Swalm, C.M. The importance of a multi-dimensional approach for studying the links between food access and consumption. J. Nutr. 2010, 140, 1170-1174. [CrossRef]

19. Jago, R.; Baranowski, T.; Baranowski, J.C. Fruit and vegetable availability: A micro environmental mediating variable? Public Health Nutr. 2007, 10, 681-689. [CrossRef]

20. Cook, L.T.; O’Reilly, G.A.; DeRosa, C.J.; Rohrbach, L.A.; Spruijt-Metz, D. Association between home availability and vegetable consumption in youth: A review. Public Health Nutr. 2015, 18, 640-648. [CrossRef]

21. Mook, K.; Laraia, B.A.; Oddo, V.M.; Jones-Smith, J.C. Food Security Status and Barriers to Fruit and Vegetable Consumption in Two Economically Deprived Communities of Oakland, California, 2013-2014. Prev. Chronic Dis. 2016, 13, E21. [CrossRef] [PubMed]

22. Seligman, H.K.; Berkowitz, S.A. Aligning programs and policies to support food security and public health goals in the United States. Ann. Rev. Publ. Health 2019, 40, 319-337. [CrossRef] [PubMed]

23. Begley, A.; Paynter, E.; Butcher, L.M.; Dhaliwal, S.S. Examining the Association between Food Literacy and Food Insecurity. Nutrients 2019, 11, 445. [CrossRef] [PubMed]

24. Davis, J.N.; Nikah, K.; Asigbee, F.M.; Landry, M.J.; Vandyousefi, S.; Ghaddar, R.; Hoover, A.; Jeans, M.; Pont, S.J.; Richards, D. Design and participant characteristics of TX sprouts: A school-based cluster randomized gardening, nutrition, and cooking intervention. Contemp. Clin. Trials 2019, 85, 105834. [CrossRef] [PubMed]

25. United States Department of Agriculture Economic Research Service: U.S. Household Food Security Survey Module: Three-stage Design, with Screeners. Available online: http://www.ers.usda.gov/topics/foodnutrition-assistance/food-security-in-the-us/survey-tools.aspx (accessed on 25 May 2020).

26. Evans, A.; Ranjit, N.; Hoelscher, D.; Jovanovic, C.; Lopez, M.; McIntosh, A.; Ory, M.; Whittlesey, L.; McKyer, L.; Kirk, A. Impact of school-based vegetable garden and physical activity coordinated health interventions on weight status and weight-related behaviors of ethnically diverse, low-income students: Study design and baseline data of the Texas, Grow! Eat! Go!(TGEG) cluster-randomized controlled trial. BMC Publ. Health 2016, 16, 973.

27. Oakley, A.; Nikolaus, C.; Ellison, B.; Nickols-Richardson, S. Food insecurity and food preparation equipment in US households: Exploratory results from a cross-sectional questionnaire. J. Hum. Nutr. Diet 2019, 32, 143-151. [CrossRef]

28. Eicher-Miller, H.A.; Zhao, Y. Evidence for the age-specific relationship of food insecurity and key dietary outcomes among US children and adolescents. Nutr. Res. Rev. 2018, 31, 98-113. [CrossRef]

29. Drewnowski, A.; Eichelsdoerfer, P. Can low-income Americans afford a healthy diet? Nutr. Today 2010, 44, 246. [CrossRef] 
30. Hough, G.; Sosa, M. Food choice in low income populations-A review. Food Qual. Prefer. 2015, 40, 334-342. [CrossRef]

31. Haynes-Maslow, L.; Auvergne, L.; Mark, B.; Ammerman, A.; Weiner, B.J. Low-income individuals' perceptions about fruit and vegetable access programs: A qualitative study. J. Nutr. Educ. Behav. 2015, 47, 317-324. [CrossRef]

32. Cassady, D.; Jetter, K.M.; Culp, J. Is price a barrier to eating more fruits and vegetables for low-income families? J. Am. Diet Assoc. 2007, 107, 1909-1915. [CrossRef]

33. Haynes-Maslow, L.; Parsons, S.E.; Wheeler, S.B.; Leone, L.A. A qualitative study of perceived barriers to fruit and vegetable consumption among low-income populations, North Carolina, 2011. Prev. Chronic Dis. 2013, 10, E34. [CrossRef] [PubMed]

34. Hollis-Hansen, K.; Vermont, L.; Zafron, M.L.; Seidman, J.; Leone, L. The introduction of new food retail opportunities in lower-income communities and the impact on fruit and vegetable intake: A systematic review. Transl Behav. Med. 2019, 9, 837-846. [CrossRef]

35. Algert, S.J.; Baameur, A.; Renvall, M.J. Vegetable output and cost savings of community gardens in San Jose, California. J. Acad. Nutr. Diet 2014, 114, 1072-1076. [CrossRef] [PubMed]

36. Carney, P.A.; Hamada, J.L.; Rdesinski, R.; Sprager, L.; Nichols, K.R.; Liu, B.Y.; Pelayo, J.; Sanchez, M.A.; Shannon, J. Impact of a community gardening project on vegetable intake, food security and family relationships: A community-based participatory research study. J. Commun. Health 2012, 37, 874-881. [CrossRef] [PubMed]

37. Algert, S.; Diekmann, L.; Renvall, M.; Gray, L. Community and home gardens increase vegetable intake and food security of residents in San Jose, California. Calif. Agric. 2016, 70, 77-82. [CrossRef]

38. Dimitri, C.; Oberholtzer, L.; Zive, M.; Sandolo, C. Enhancing food security of low-income consumers: An investigation of financial incentives for use at farmers markets. Food Policy 2015, 52, 64-70. [CrossRef]

39. Pitts, S.B.J.; Gustafson, A.; Wu, Q.; Mayo, M.L.; Ward, R.K.; McGuirt, J.T.; Rafferty, A.P.; Lancaster, M.F.; Evenson, K.R.; Keyserling, T.C. Farmers' market use is associated with fruit and vegetable consumption in diverse southern rural communities. Nutr. J. 2014, 13, 1. [CrossRef]

40. Savoie-Roskos, M.; Durward, C.; Jeweks, M.; LeBlanc, H. Reducing food insecurity and improving fruit and vegetable intake among farmers' market incentive program participants. J. Nutr. Educ. Behav. 2016, 48, 70-76. [CrossRef]

41. Steele-Adjognon, M.; Weatherspoon, D. Double Up Food Bucks program effects on SNAP recipients' fruit and vegetable purchases. BMC Publ. Health 2017, 17, 946. [CrossRef] [PubMed]

42. Bradford, V.A.; Quinn, E.L.; Walkinshaw, L.P.; Rocha, A.; Chan, N.L.; Saelens, B.E.; Johnson, D.B. Fruit and vegetable access programs and consumption in low-income communities. J. Hunger Environ. Nutr. 2019, 14, 780-795. [CrossRef]

43. Wetherill, M.S.; Gray, K.A. Farmers' markets and the local food environment: Identifying perceived accessibility barriers for SNAP consumers receiving temporary assistance for needy families (TANF) in an urban Oklahoma community. J. Nutr. Educ. Behav. 2015, 47, 127-133. [CrossRef] [PubMed]

44. Grindal, T.; Wilde, P.; Schwartz, G.; Klerman, J.; Bartlett, S.; Berman, D. Does food retail access moderate the impact of fruit and vegetable incentives for SNAP participants? Evidence from western Massachusetts. Food Policy 2016, 61, 59-69. [CrossRef]

45. Allcott, H.; Diamond, R.; Dubé, J.-P.; Handbury, J.; Rahkovsky, I.; Schnell, M. Food deserts and the causes of nutritional inequality. Q. J. Econ. 2019, 134, 1793-1844. [CrossRef]

46. Vidgen, H.A.; Gallegos, D. Defining food literacy and its components. Appetite 2014, 76, 50-59. [CrossRef]

47. Monsivais, P.; Aggarwal, A.; Drewnowski, A. Time spent on home food preparation and indicators of healthy eating. Am. J. Prev. Med. 2014, 47, 796-802. [CrossRef]

48. Saksena, M.J.; Okrent, A.M.; Anekwe, T.D.; Cho, C.; Dicken, C.; Effland, A.; Elitzak, H.; Guthrie, J.; Hamrick, K.S.; Hyman, J. America's Eating Habits: Food away from Home; United States Department of Agriculture, Economic Research Service: Washington, DC, USA, 2018.

49. Taillie, L.S. Who's cooking? Trends in US home food preparation by gender, education, and race/ethnicity from 2003 to 2016. Nutr. J. 2018, 17, 41. [CrossRef]

50. Mclaughlin, C.; Tarasuk, V.; Kreiger, N. An examination of at-home food preparation activity among low-income, food-insecure women. J. Am. Diet Assoc. 2003, 103, 1506-1512. [CrossRef] 
51. Fiese, B.H.; Gundersen, C.; Koester, B.; Jones, B. Family chaos and lack of mealtime planning is associated with food insecurity in low income households. Econ. Hum. Biol. 2016, 21, 147-155. [CrossRef]

52. Knol, L.L.; Robb, C.A.; McKinley, E.M.; Wood, M. Very low food security status is related to lower cooking self-efficacy and less frequent food preparation behaviors among college students. J. Nutr. Educ. Behav. 2019, 51, 357-363. [CrossRef]

53. Landry, M.J.; Markowitz, A.K.; Asigbee, F.M.; Gatto, N.M.; Spruijt-Metz, D.; Davis, J.N. Cooking and Gardening Behaviors and Improvements in Dietary Intake in Hispanic/Latino Youth. Child Obes. 2019, 15, 262-270. [CrossRef]

54. Allirot, X.; da Quinta, N.; Chokupermal, K.; Urdaneta, E. Involving children in cooking activities: A potential strategy for directing food choices toward novel foods containing vegetables. Appetite 2016, 103, 275-285. [CrossRef] [PubMed]

55. Overcash, F.; Ritter, A.; Mann, T.; Mykerezi, E.; Redden, J.; Rendahl, A.; Vickers, Z.; Reicks, M. Impacts of a vegetable cooking skills program among low-income parents and children. J. Nutr. Educ. Behav. 2018, 50, 795-802. [CrossRef] [PubMed]

56. Fleischhacker, S.; Parks, C.A.; Yaroch, A.L. Addressing food insecurity in the United States: The role of policy, systems changes, and environmental supports. Transl. Behav. Med. 2019, 9, 827-836. [CrossRef] [PubMed]

(C) 2020 by the authors. Licensee MDPI, Basel, Switzerland. This article is an open access article distributed under the terms and conditions of the Creative Commons Attribution (CC BY) license (http://creativecommons.org/licenses/by/4.0/). 